\title{
On overhead networks transfer from 10(6) kV to $20 \mathrm{kV}$
}

\author{
Andrey Mayorov ${ }^{1}$, Kirill Osintsev ${ }^{2}$, and Andrey Shuntov ${ }^{2}$ \\ ${ }^{1}$ Public company «United Energy Company», 115035 Raushskaya Naberezhnaya, 8, Russian Federation \\ ${ }^{2}$ National Research University «Moscow Power Engineering Institute», 111250 Krasnokazarmennaya 14, Russian Federation
}

\begin{abstract}
The expediency of preferential use of the rated voltage of $20 \mathrm{kV}$ for the overhead networks of Russia is investigated. The feasibility study of the $20 \mathrm{kV}$ voltage application areas based on the integrated parameters of the networks was performed. It is shown that due to the convergence of technical and economic characteristics of 10 and $20 \mathrm{kV}$ equipment, $20 \mathrm{kV}$ networks have more significant advantages in comparison with traditional $10 \mathrm{kV}$ electrical installations.
\end{abstract}

\section{Introduction}

Feasibility of using $20 \mathrm{kV}$ electric networks in our country has a long history. This voltage class was included into the list of rated voltage scale and then excluded again [1]. It was alleged that "...the introduction of $20 \ldots \mathrm{kV}$ voltage is not necessary...". There were other opinions $[2,3$, etc.]: "... the overhead networks require significantly lower costs, non-ferrous metals and especially transformer capacities... for $110 / 20 \mathrm{kV}$ system with a direct 20/0.4 kV transformation...". When comparing alternatives of 10 and $20 \mathrm{kV}$ networks it was assumed [3] that the cost parameters of overhead lines (OHL) and transformer substations (TS) of 20/0.4 $\mathrm{kV}$ exceed similar characteristics of $10 \mathrm{kV} \mathrm{OHL}$ and $10 / 0.4 \mathrm{kV}$ TS in 1.1 and 1.25 times respectively.

The widespread construction of $20 \mathrm{kV}$ electric networks in the country began after almost half a century, about five years ago in Moscow [4]. To date, more than $1,000 \mathrm{~km}$ of $20 \mathrm{kV}$ cable lines have been commissioned. The construction of cable networks of this voltage class is also carried out in St. Petersburg and Yekaterinburg.

$20 \mathrm{kV}$ overhead networks of suburban and agricultural areas have their own specifics and have not been used all-round the country. The grounds on technical and economic efficiency of $20 \mathrm{kV}$ voltage class application in overhead networks are presented below.

\section{Integral network parameters}

The methods for solving such optimization problems are well-known. The first one is referred to as the method of idealized structures, the second one is analytical. An example of the first approach is presented in the paper [1]. In this work, the network topology is given in the form of a lattice with a given step. TS are located in its nodes. Alternatives of the network are compared by the minimum cost through variation of initial data - load density, distances between nodes of the network, etc. In the second method, the cost indicators of OHL and TS are specified in the form of analytical (usually approximating) functions depending on their parameters (voltage, wire cross-section, line length, current, power, etc.). The extremum point is identified, for example, as in [5] - with the use of undetermined Lagrange multipliers.

The drawback of the first method is the divorcement from the actual structure and parameters of the network. The second method is even weaker, since it considers [5] the simplest configuration of the network: the power source - the load node.

We will analyse overhead networks of $10(6) \mathrm{kV}$ in 18 districts of a large electric grid company from the European part of the country. In each district, typical network fragments were allocated according to the form shown in Fig. 1 [4].

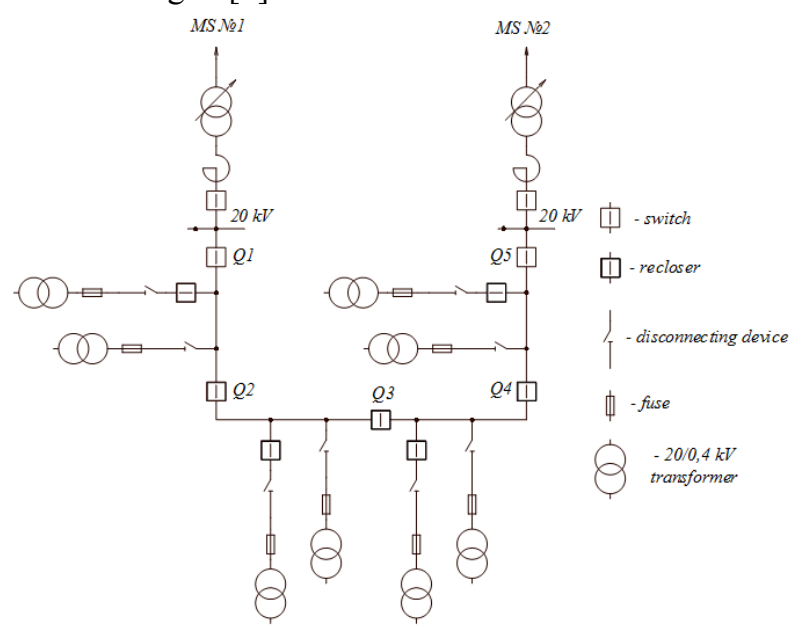

Fig. 1. Typical configuration of the overhead network.

Network fragments are connected in a loop and sourced by two geo-graphically separated main substations (MS) of $110 / 10(6) \mathrm{kV}$ and sectionalized by reclosers, i.e. automatic posts of OHL sectionalizing. Transformer 
substations of $10(6) / 0.4$ are connected to the backbone transmission line with a disconnector or recloser for long distance branches. Protection of 10(6)/0.4 transformers is carried out by fuses on the $10(6) \mathrm{kV}$ side. In normal operation mode, the network is separated by one of the reclosers with automatic load transfer (ALT). Mainly, one-transformer TS of pole-mounted (PTS, nominal transformer power $S_{\text {nom }}$ is $16-100 \mathrm{kV} \cdot \mathrm{A}$ ), mast (MTS, $\left.\mathrm{S}_{\text {nom }}=160-250 \mathrm{kV} \cdot \mathrm{A}\right)$ and kiosk (KTS, $\mathrm{S}_{\text {nom }}=400$ $1000 \mathrm{kV} \cdot \mathrm{A}$ ) types are installed.

In Table 1 the parameters relating to the linear part of the above-mentioned 18 network fragments are given: $\mathrm{P}_{\max }$ and $\mathrm{P}_{\min }$ - peak winter and summer load based on measurements of $2016 ; 1_{\mathrm{OHL}}$ and $1_{\mathrm{OHLP}}$ - the length of the line made of uninsulated wires and wires with a protective insulating sheath (OHLP); $1_{C L}$ - the same for cable lines; $1_{\text {total }}$ - the total length of the lines; $1_{\text {back }}-$ the length of the backbone transmission line between the PC (without regard for the branches); $\sigma_{\mathrm{ld}}$ is the load density; $\sigma_{\mathrm{n}}$ is the network density.

Table 1. Parameters of the linear part of network fragments.

\begin{tabular}{|c|c|c|c|c|c|c|c|c|}
\hline Frag & $\begin{array}{c}\mathrm{P}_{\max } / \mathrm{P}_{\min } \\
\mathrm{kW} / \mathrm{kW}\end{array}$ & $\begin{array}{l}1_{\mathrm{OHL}} \\
\mathrm{km}\end{array}$ & $\begin{array}{c}1_{\mathrm{OHLP}} \\
\mathrm{km}\end{array}$ & $\begin{array}{l}\mathrm{l}_{\mathrm{CL}} \\
\mathrm{Km}\end{array}$ & $\begin{array}{l}1_{\text {total }} \\
\mathrm{km}\end{array}$ & $\begin{array}{l}1_{\text {back }} \\
\mathrm{Km}\end{array}$ & $\begin{array}{c}\sigma_{\mathrm{ld}} \\
\mathrm{kW} / \mathrm{km}^{2}\end{array}$ & $\begin{array}{c}\sigma_{\mathrm{n}} \\
\mathrm{km} / \mathrm{km}^{2}\end{array}$ \\
\hline 1 & \begin{tabular}{|c|}
$3138 /$ \\
1642
\end{tabular} & 24.2 & 9.7 & 6.8 & 40.7 & 19.8 & 129.1 & 1.7 \\
\hline 2 & $\begin{array}{l}4751 / \\
3168 \\
\end{array}$ & 32.6 & 8.6 & 11.2 & 52.4 & 19.4 & 154.3 & 1.7 \\
\hline 3 & $\begin{array}{l}7358 / \\
5816\end{array}$ & 67.5 & 2.6 & 4.0 & 74.1 & 32.6 & 154.3 & 1.6 \\
\hline 4 & $\begin{array}{c}3609 / \\
1929\end{array}$ & 49.7 & 13.5 & 6.9 & 70.1 & 21.0 & 83.2 & 1.6 \\
\hline 5 & $\begin{array}{l}6646 / \\
6072\end{array}$ & 35.4 & 49.2 & 3.0 & 87.6 & 43.0 & 157.3 & 2.1 \\
\hline 6 & $\begin{array}{c}1781 / \\
989\end{array}$ & 44.7 & 0.6 & 1.6 & 46.9 & 12.9 & 57.3 & 1.5 \\
\hline 7 & $\begin{array}{c}1840 / \\
844\end{array}$ & 40.6 & 0.4 & 1.5 & 42.5 & 22.5 & 45.5 & 1.0 \\
\hline 8 & $\begin{array}{l}2486 / \\
1244 \\
\end{array}$ & 32.8 & 3.3 & 0.1 & 36.2 & 22.0 & 66.8 & 1.0 \\
\hline 9 & $\begin{array}{c}2992 / \\
1673\end{array}$ & 51.8 & 7.5 & 3.1 & 62.4 & 35.8 & 55.0 & 1.0 \\
\hline 10 & $\begin{array}{l}3101 / \\
2436\end{array}$ & 52.8 & 11.9 & 11.0 & 75.7 & 38.3 & 45.1 & 1.1 \\
\hline 11 & $\begin{array}{c}2716 / \\
1338 \\
\end{array}$ & 20.1 & 0.0 & 6.4 & 26.5 & 13.8 & 110.4 & 1.1 \\
\hline 12 & $\begin{array}{c}2818 / \\
1934\end{array}$ & 46.4 & 4.9 & 3.0 & 54.3 & 29.6 & 72.3 & 1.4 \\
\hline 13 & $\begin{array}{l}1640 / \\
1102\end{array}$ & 59.8 & 2.0 & 2.8 & 64.6 & 31.0 & 39.8 & 1.6 \\
\hline 14 & $\begin{array}{c}1193 / \\
618\end{array}$ & 49.5 & 10.1 & 2.2 & 61.8 & 41.3 & 24.8 & 1.3 \\
\hline 15 & $\begin{array}{l}956 / \\
349 \\
\end{array}$ & 43.0 & 7.0 & 0.0 & 50.0 & 30.9 & 26.3 & 1.4 \\
\hline 16 & $\begin{array}{c}297 / \\
78\end{array}$ & 35.0 & 0.0 & 0.0 & 35.0 & 30.5 & 8.2 & 1.0 \\
\hline 17 & $\begin{array}{c}3023 / \\
1872 \\
\end{array}$ & 21.0 & 11.4 & 9.9 & 42.3 & 20.3 & 117.6 & 1.6 \\
\hline 18 & $\begin{array}{c}1484 / \\
796\end{array}$ & 102.9 & 3.8 & 0.3 & 107.0 & 38.5 & 21.7 & 1.6 \\
\hline Aver. & $\begin{array}{c}2879 / \\
1833\end{array}$ & 45.0 & 8.1 & 4.1 & 57.2 & 28.0 & 76.1 & 1.4 \\
\hline
\end{tabular}

The power supply area for assessing $\sigma_{\mathrm{ld}}$ and $\sigma_{\mathrm{n}}$ was determined on the assumption that the coverage radius of the $0.4 \mathrm{kV}$ network of $10(6) / 0.4 \mathrm{kV}$ TS composes not more than $0.5 \mathrm{~km}$. Accordingly, the width of the corridor of $10(6) \mathrm{kV}$ OHL is $1 \mathrm{~km}$ when determining the area.

In fact, the entire overhead network (Table 1) is made with a wire of $70 \mathrm{~mm}^{2}$, except fragments No. 5 and 17 where cross-section of $120 \mathrm{~mm}^{2}$ is used for backbone transmission lines.

Table 2 shows the parameters relating to the TS of network fragments: $S_{\text {total }}$ - the total installed capacity of $10(6) / 0.4 \mathrm{kV}$ step-down transformers; $1_{\mathrm{TS}}$ - the average distance between the TS; $\sigma_{\mathrm{TS}}-\mathrm{TS}$ density; ITS - indoor TS.

Table 2. Parameters of the transformer part of network fragments.

\begin{tabular}{|c|c|c|c|c|c|c|c|c|c|}
\hline \multirow[t]{2}{*}{ Frag } & \multirow{2}{*}{$\begin{array}{l}\mathrm{P}_{\max } / \mathrm{P}_{\min } \\
\mathrm{kW} / \mathrm{kW}\end{array}$} & \multirow{2}{*}{$\begin{array}{r}\mathrm{S}_{\text {total }} \\
\mathrm{kV} \cdot \mathrm{A}\end{array}$} & \multicolumn{4}{|c|}{ Amount, pcs } & \multirow{2}{*}{$\begin{array}{l}\mathrm{l}_{\mathrm{TS}} \\
\mathrm{km}\end{array}$} & \multicolumn{2}{|c|}{$\sigma_{\mathrm{TS}}$} \\
\hline & & & ITS & KTS & $\begin{array}{l}\text { PTS, } \\
\text { MTS }\end{array}$ & Total & & $\begin{array}{c}\mathrm{kV} \cdot \mathrm{A} / \\
\mathrm{km}^{2}\end{array}$ & $\begin{array}{l}\mathrm{pcs} / \\
\mathrm{km}^{2}\end{array}$ \\
\hline 1 & $\begin{array}{l}3138 / \\
1642\end{array}$ & 11700 & 4 & 36 & 8 & 48 & 0.85 & 483 & 2.0 \\
\hline 2 & $\begin{array}{l}4751 / \\
3168\end{array}$ & 15600 & 14 & 44 & 6 & 64 & 0.82 & 507 & 2.1 \\
\hline 3 & $\begin{array}{l}7358 / \\
5816\end{array}$ & 18900 & 11 & 69 & 7 & 87 & 0.85 & 396 & 1.8 \\
\hline 4 & $\begin{array}{c}3609 / \\
1929\end{array}$ & 12300 & 14 & 50 & 7 & 71 & 0.99 & 285 & 1.6 \\
\hline 5 & $\begin{array}{c}6646 / \\
6072 \\
\end{array}$ & 23600 & 13 & 82 & 15 & 110 & 0.80 & 559 & 2.6 \\
\hline 6 & $\begin{array}{c}1781 / \\
989\end{array}$ & 6600 & 2 & 42 & 10 & 54 & 0.87 & 213 & 1.7 \\
\hline 7 & $\begin{array}{c}1840 / \\
844\end{array}$ & 8200 & 6 & 31 & 7 & 44 & 0.97 & 204 & 1.1 \\
\hline 8 & $\begin{array}{c}2486 / \\
1244\end{array}$ & 5000 & 3 & 29 & 6 & 38 & 0.95 & 135 & 1.0 \\
\hline 9 & $\begin{array}{c}2992 / \\
1673\end{array}$ & 7600 & 0 & 47 & 0 & 47 & 1.33 & 140 & 0.9 \\
\hline 10 & $\begin{array}{l}3101 / \\
2436\end{array}$ & 11300 & 0 & 66 & 1 & 67 & 1.13 & 164 & 1.0 \\
\hline 11 & $\begin{array}{c}2716 / \\
1338 \\
\end{array}$ & 6300 & 0 & 20 & 0 & 20 & 1.33 & 255 & 0.8 \\
\hline 12 & $\begin{array}{l}2818 / \\
1934 \\
\end{array}$ & 9700 & 3 & 17 & 40 & 60 & 0.91 & 248 & 1.5 \\
\hline 13 & $\begin{array}{l}1640 / \\
1102\end{array}$ & 7800 & 6 & 10 & 41 & 57 & 1.13 & 189 & 1.4 \\
\hline 14 & $\begin{array}{c}1193 / \\
618\end{array}$ & 6300 & 6 & 6 & 34 & 46 & 1.34 & 130 & 1.0 \\
\hline 15 & $\begin{array}{l}956 / \\
349\end{array}$ & 9200 & 13 & 12 & 8 & 33 & 1.52 & 252 & 0.9 \\
\hline 16 & $\begin{array}{c}297 / \\
78 \\
\end{array}$ & 2900 & 4 & 9 & 2 & 15 & 2.33 & 81 & 0.4 \\
\hline 17 & $\begin{array}{l}3023 / \\
1872\end{array}$ & 10000 & 13 & 36 & 7 & 56 & 0.76 & 389 & 2.2 \\
\hline 18 & $\begin{array}{c}1484 / \\
796\end{array}$ & 11700 & 15 & 48 & 5 & 68 & 1.57 & 171 & 1.0 \\
\hline Aver. & $\begin{array}{l}2879 / \\
1833\end{array}$ & 10300 & 7 & 36 & 11 & 54 & 1.14 & 267 & 1.4 \\
\hline
\end{tabular}

Analysis of data from Tables 1 and 2 allows to establish some statistical patterns:

1. The length of the $10(6) \mathrm{kV}$ backbone line between the MS varies from 12.9 to $41.3 \mathrm{~km}$ with an average value of $28.0 \mathrm{~km}$, which shows a relative uniformity of the MS distribution in the region.

2. The load density varies over a wide range from 8.2 to $157.3 \mathrm{~kW} / \mathrm{km}^{2}$ (average $76.1 \mathrm{~kW} / \mathrm{km}^{2}$ ). The range of average distances between TS in the fragments is $0.76-$ 
$2.33 \mathrm{~km}$ (average $1.14 \mathrm{~km}$ ), which indicates a relatively uniform TS distribution over the territory.

3. The installed capacity of $10(6) / 0,4 \mathrm{kV}$ TS is $2-9$ times higher than the actual maximum load, which is clearly irrational.

For comparison, the authors of [1] in their conclusions relied on the following data on the load density: in industrial areas it reaches $30-40 \mathrm{~kW} / \mathrm{km}^{2}$ (average $20 \mathrm{~kW} / \mathrm{km}^{2}$ ), in electrified agricultural areas does not exceed $2-3 \mathrm{~kW} / \mathrm{km}^{2}$. For the 70 years passed since, the load density has multiply increased, which is an incentive to increase the nominal voltage of the network.

\section{Technical and economic aspects of using $20 \mathrm{kV}$ OHL}

When transferring from 10 to $20 \mathrm{kV}$, the phase-to-phase distances increase slightly (from 0.2 to $0.45 \mathrm{~m}$ ) in case of uninsulated wires [6] and there is no difference $(0.4 \mathrm{~m})$ when using OHLP. However, the actual phase-to-phase distances for typical reinforced concrete supports are approximately 2.5 times larger [7]. Therefore, for the same cross-section and wire type, the mechanical part of the 10 and $20 \mathrm{kV} \mathrm{OHL}$ is identical, except the number and rated voltage of the insulators in some cases, the cost of which is an insignificant part of the costs of OHL [8]. Therefore, capital investments to 10 and $20 \mathrm{kV}$ overhead lines differ by not more than $1 \%$.

The cost of constructing a $10-20 \mathrm{kV}$ OHL in the European part of the country (hereinafter in 2017 prices without VAT) is determined by the simplest linear dependencies in the range of nominal cross sections from 50 to $120 \mathrm{~mm}^{2}$ with a maximum error of $1.4 \%$ : for uninsulated steel-aluminum wires $\mathrm{C}_{\mathrm{OHL}}=665.1+2.21 \mathrm{~s}$ and $\mathrm{C}_{\mathrm{OHL}}=497.5+2.18 \mathrm{~s}$ th.RUB $/ \mathrm{km}$ in populated and unpopulated areas respectively. Similarly, for insulated wires: $\quad \mathrm{C}_{\mathrm{OHLP}}=861.8+2.86 \mathrm{~s}$ and $\mathrm{C}_{\mathrm{OHLP}}=665.8+2.86 \mathrm{~s}$ th.RUB/km

When calculating discounted costs, the cost of OHL construction must be multiplied by the increasing factor $\mathrm{K}=1+\mathrm{k}_{1} \mathrm{k}_{2}=1+0.0085 \cdot 9.4=1.8$, where $\mathrm{k}_{1}$ stands for repairs and maintenance; $\mathrm{k}_{2}=\frac{(1+\mathrm{E})^{\mathrm{n}}-1}{\mathrm{E}(1+\mathrm{E})^{\mathrm{n}}} ; \mathrm{E}-$ discount factor; $\mathrm{n}$ is the design lifetime of the electrical installation calculated from the moment of commissioning. Thus, at $\mathrm{E}=0.1$ and $\mathrm{n}=30$ years, $\mathrm{k}_{2}=9.4$.

Moreover, it is necessary to take into account the cost of electric power losses for the design lifetime $\mathrm{C}_{\Delta \mathrm{W}}=\Delta \mathrm{P}_{\max } \tau \mathrm{C}_{\mathrm{e}} \mathrm{k}_{2}$, where $\Delta \mathrm{P}_{\max }$ - the power losses in the peak loading conditions; $\tau$ - annual time of maximum losses; $\mathrm{C}_{\mathrm{e}}-$ the unit cost of electric power losses. As it is known, $\tau=f\left(T_{\max }\right)$, where $\mathrm{T}_{\max }-$ the number of hours of maximum load. According to the current reporting data for the region under consideration, $\mathrm{T}_{\max } \approx 6000 \mathrm{~h}$ $(\tau=3800 \mathrm{~h})$ and $\mathrm{C}_{\mathrm{e}}=2.18 \mathrm{RUB} / \mathrm{kWh}$.

\section{Technical and economic aspects of using $20 \mathrm{kV}$ TS}

Currently, domestic factories produce all the range of $20 \mathrm{kV}$ TS elements. Power transformer of TMG type, used in TS of 10 and $20 \mathrm{kV}$, has the same weight and dimensions. The main difference is the height of highvoltage bushings (for $20 \mathrm{kV} 75 \mathrm{~mm}$ higher than for $10 \mathrm{kV}$ ). For actual air insulation gaps between the fuse block and the transformer in $10 \mathrm{kV}$ PTS and MTS, such an increase in bushings is not critical. The same relates to KTS transformer chambers.

The cost of 20/0.4 kV PTS is approximately $20-25 \%$ higher than of $10 / 0.4 \mathrm{kV}$ PTS. In general, the rise in price is due to the higher price of transformers and disconnectors. The cost of TS constructing is determined by the simplest linear dependencies at the highest error of $3.6 \%$ : for PTS $\mathrm{C}_{\mathrm{PTS}}=273+\mathrm{S}_{\text {nom }}+11.56 \mathrm{U}_{\text {nom }}$; for MTS $\mathrm{C}_{\mathrm{MTS}}=178+1.16 \mathrm{~S}_{\mathrm{nom}}+15.32 \mathrm{U}_{\text {nom; }}$; for $\mathrm{KTS}$ $\mathrm{C}_{\mathrm{KTS}}=401+1.29 \mathrm{~S}_{\text {nom }}+25.94 \mathrm{U}_{\text {nom }}$. For the TS, $\mathrm{K}=1+\mathrm{k}_{1} \mathrm{k}_{2}=1+0.037 \cdot 9.4=1.35$. According to the factory data, the idling and short circuit losses of 10/0.4 and $20 / 0.4 \mathrm{kV}$ transformers are the same and are further excluded from consideration.

The types of TS considered above have principal structural differences. Therefore, their costs are not jointly approximated with acceptable accuracy.

\section{Comparison of the 10 and $20 \mathrm{kV}$ network options}

Table 3 shows the discounted costs (mln. RUB) for constructing networks fragments with the characteristics from Tables 1 and 2 at 10 and $20 \mathrm{kV}: \mathrm{C}_{\mathrm{TS}}-$ costs for TS while maintaining their installed capacities; $\mathrm{C}_{\text {total }}=\mathrm{C}_{\mathrm{L}}+\mathrm{C}_{\Delta \mathrm{W}}+\mathrm{C}_{\mathrm{TS}}$ - total expenses of the electric network; $\Delta-$ the ratio of total expenses of the electrical networks of 10 and $20 \mathrm{kV}$.

Table 3. Discounted costs for constructing network fragments.

\begin{tabular}{|c|c|c|c|c|c|c|c|c|}
\hline \multirow{2}{*}{ Frag } & $\mathrm{C}_{\mathrm{L}}$ & \multicolumn{2}{|c|}{$\mathrm{C}_{\Delta \mathrm{W}}$} & \multicolumn{2}{c|}{$\mathrm{C}_{\mathrm{TS}}$} & \multicolumn{2}{c|}{$\mathrm{C}_{\text {total }}$} & \multirow{2}{*}{\begin{tabular}{c}
$\Delta$ \\
\cline { 3 - 8 }
\end{tabular}} \\
\cline { 2 - 8 } & $10 \mathrm{kV}$ & $20 \mathrm{kV}$ & $10 \mathrm{kV}$ & $20 \mathrm{kV}$ & $10 \mathrm{kV}$ & $20 \mathrm{kV}$ & $\%$ \\
\hline 1 & 37.8 & 17.6 & 4.1 & 48.8 & 60.3 & 104.2 & 102.2 & 102 \\
\hline 2 & 48.6 & 28.7 & 6.3 & 66.3 & 80.6 & 143.3 & 135.5 & 106 \\
\hline 3 & 68.9 & 287.8 & 70.2 & 82.9 & 101.8 & 439.6 & 250.9 & 175 \\
\hline 4 & 65.1 & 77.8 & 20.8 & 63.1 & 78.2 & 206.0 & 164.1 & 126 \\
\hline 5 & 81.4 & 306.5 & 74.7 & 107.1 & 131.5 & 495.0 & 287.6 & 172 \\
\hline 6 & 43.6 & 6.0 & 1.3 & 39.5 & 49.0 & 89.1 & 93.9 & 95 \\
\hline 7 & 39.5 & 8.9 & 2.0 & 38.7 & 47.8 & 87.1 & 89.3 & 98 \\
\hline 8 & 33.6 & 11.5 & 2.6 & 28.9 & 35.9 & 74.0 & 72.1 & 103 \\
\hline 9 & 62.4 & 42.6 & 8.1 & 40.6 & 50.7 & 145.6 & 121.2 & 120 \\
\hline 10 & 70.4 & 25.1 & 5.2 & 58.1 & 72.2 & 153.6 & 147.8 & 104 \\
\hline 11 & 24.6 & 5.2 & 1.4 & 24.8 & 30.2 & 54.6 & 56.2 & 97 \\
\hline 12 & 50.4 & 15.3 & 3.1 & 50.8 & 62.4 & 116.5 & 115.9 & 101 \\
\hline 13 & 60.0 & 10.2 & 2.3 & 43.4 & 54.1 & 113.6 & 116.4 & 98 \\
\hline 14 & 57.4 & 4.5 & 1.0 & 35.2 & 43.5 & 97.1 & 101.9 & 95 \\
\hline 15 & 46.5 & 3.1 & 0.8 & 40.5 & 50.0 & 90.1 & 97.3 & 93 \\
\hline 16 & 32.6 & 0.2 & $\approx 0$ & 12.2 & 15.3 & 45.0 & 47.9 & 94 \\
\hline 17 & 39.3 & 38.4 & 7.9 & 47.1 & 57.6 & 124.8 & 104.8 & 119 \\
\hline 18 & 99.4 & 11.9 & 2.7 & 41.5 & 50.5 & 152.8 & 152.6 & 100 \\
\hline
\end{tabular}


The wire cross-section was taken to be equal to the actual value (mainly $70 \mathrm{~mm}^{2}$ - see above) and the same for the backbone sections and branches. The cost of OHL construction $C_{L}$ was estimated by the average value between the minimum and maximum estimates; the minimum -650 th.RUB $/ \mathrm{km}$ at a voltage of 10 and $20 \mathrm{kV}$ for uninsulated wires in unpopulated areas; the maximum - 1070 th.RUB $/ \mathrm{km}$ for insulated wire in the populated area; an average is 860 th.RUB $/ \mathrm{km}$ without taking into account the factor $\mathrm{K}$. When determining the cost of electric power losses in the overhead line, an annual load increase is taken to be equal to $2 \%$.

It should be noted that the component $\mathrm{C}_{\Delta \mathrm{W}}$ from Table 3 differs by more than four times for 10 and $20 \mathrm{kV}$ voltages: when calculating steady-state modes, no restrictions on the minimum voltage values at the network nodes were imposed. Therefore, for the $10 \mathrm{kV}$ network fragments No. 1, 9, 10 from Table 3, the voltage in the network nodes decreased significantly (more than $10 \%$ ) in the normal mode, while in the alternative $20 \mathrm{kV}$ network it was at the rated level. For fragments No. 3-5 there was no mode convergence for $10 \mathrm{kV}$ network. Here the cost of electric power losses is determined formally, by a multiple increase in losses in the $20 \mathrm{kV}$ network.

The required voltage quality should be provided in accordance with State regulations GOST 32144-2013 not only in normal, but also in continuous repair and post-emergency operation modes - voltage reduction cannot exceed $10 \%$ of the rated value. In the $10 \mathrm{kV}$ network this requirement is not satisfied for fragments No. 1-6, 9, 10, 12-14 at the current loading conditions and all fragments, except No. 16, in the prospective. Thus, in the foreseeable future, a deep reconstruction of practically the entire $10 \mathrm{kV}$ network will be required (disaggregation of the backbone sections due to their diversion to other power centers), which is not taken into account in Table 3 . In the alternative $20 \mathrm{kV}$ network, the required quality is not provided only in the fragment No. 3 at the current load conditions and also in the fragment No. 10 for the perspective load growth. Thus, when using $20 \mathrm{kV}$ voltage, measures to increase the network capacity will be local and significantly less expensive.

The existing approach to the comparison of diagrams of electrical networks with different levels of rated voltages is to be referred to as [9]: "The criterion for choosing a voltage system is the total costs for networks of all classes of voltage. When comparing the options of electrical networks with different voltage classes having equal costs or costs, differing up to $10 \%$, priority is given to the option of developing networks with a higher average voltage of the distribution network". There is a certain logic in this: $10 \%$ is the generally accepted engineering accuracy of calculations, especially under conditions of great uncertainty in decision-making.

In our case, with a fixed cross-section of the wire, the capacity of the $20 \mathrm{kV}$ network is twice as high as at $10 \mathrm{kV}$, and with the same transmitted power, the power losses are approximately four times less. This is a significant advantage of the electrical network of $20 \mathrm{kV}$. As can be seen from Table 3, according to the indicated criteria the transfer from $10 \mathrm{kV}$ to $20 \mathrm{kV}$ is reasonable practically for all the variety of values of the network parameters from Tables 1 and 2.

\section{Questions of optimization of electric network parameters}

For example, the cost function $\mathrm{C}_{\mathrm{OHLP}}=665.8+2.86 \mathrm{~s}$ th.RUB $/ \mathrm{km}$ is taken. Let's pass to the discounted costs $\mathrm{C}_{\mathrm{OHLP}}=\mathrm{K}(665.8+2.86 \mathrm{~s})=1.08(665.8+2.86 \mathrm{~s})=719+3.1 \mathrm{~s}$ th.RUB $/ \mathrm{km}$. The discounted cost of electric power losses for $1 \mathrm{~km}$ of a three-phase line is $\mathrm{C}_{\Delta \mathrm{W}}=\Delta \mathrm{P}_{\max } \tau \mathrm{C}_{\mathrm{e}} \mathrm{k}_{2}=$ $3 \mathrm{I}^{2} \mathrm{R} \tau \mathrm{C}_{\mathrm{e}} \mathrm{k}_{2}=3 \mathrm{I}^{2}(\mathrm{\rho l} / \mathrm{s}) \tau \mathrm{C}_{\mathrm{e}} \mathrm{k}_{2}=$ $=3 \mathrm{I}^{2}\left(0.0376 \cdot 10^{3} / \mathrm{s}\right) 10^{-3} \cdot 3800 \cdot 2.18 \cdot 10^{-3} \cdot 9.4=8.7 \mathrm{I}^{2} / \mathrm{s}$, th.RUB $/ \mathrm{km}$, where I - the phase current, A; R resistance, Ohm; $\rho$ - the specific resistance of the aluminum alloy conductor at an average temperature of $57^{\circ} \mathrm{C}$ (between the nominal 25 and the largest $90^{\circ} \mathrm{C}$ ), $\mathrm{Ohm} \cdot \mathrm{mm}^{2} / \mathrm{m} ; 1$ - the length of the line, $\mathrm{km}$. Therefore, the total discounted costs on OHL are:

$$
C_{\mathrm{L}}=C_{\mathrm{OHLP}}+C_{\Delta \mathrm{W}}=719+3.1 s+8.7 I^{2} / s, \text { th. RUB } / \mathrm{km} \text {. }
$$

Consequently, the optimal cross-section of the wire will be:

$$
\begin{gathered}
\partial C_{\mathrm{L}} / \partial s=3.1-8.7 I^{2} / s^{2}=0 \\
s=\sqrt{8,7 / 3,1} I
\end{gathered}
$$

From which the "economic" current density is $\mathrm{j}_{0}=\mathrm{I} / \mathrm{s}=1 / \sqrt{8,7 / 3,1}=0.6 \mathrm{~A} / \mathrm{mm}^{2} . \quad$ The authors intentionally quoted the word "economic" in order to avoid the continuation of many years of discussions [ 10 , 11 , etc.] in this field. By the way, the same value of 0.6 $\mathrm{A} / \mathrm{mm}^{2}$ appeared in [5]. The use of the cost characteristics of another type of OHL in (1)-(3) (see above) leads to a change of $\mathrm{j}_{0}$ by no more than $10 \%$.

For a cross section of conductors of $70 \mathrm{~mm}^{2}$, the current will be $0.6 \cdot 70=42$ A or power of $S \approx 730 \mathrm{kV} \cdot \mathrm{A}$ at a voltage of $10 \mathrm{kV}$. For the configurations in Fig. 1 and Table 1, the power of a typical network fragment is estimated as $2 \mathrm{~S} \approx 1460 \mathrm{kV} \cdot \mathrm{A}$. This ratio is satisfied only by case studies No. 14-16 from Table 1, which indicates an imbalance: overloaded OHL with redundant excess of transformer capacity.

When transferring to a voltage of $20 \mathrm{kV}$ at the same section of the OHL wires, there is $2 \mathrm{~S} \approx 2920 \mathrm{kV} \cdot \mathrm{A}$. In this case, already more than half of network fragments have satisfactory indicators from the point of $\mathrm{j} 0$. For the remainder of the fragments, it is advisable to further increase the cross section of the conductors to $120 \mathrm{~mm} 2$ $(2 \mathrm{~S} \approx 5800 \mathrm{kV} \cdot \mathrm{A})$. However, this is clearly not enough for fragments No. 3 and 5 from Table 1. They should be disaggregated. Accounting for the growth of loads, which was not taken into account in (1), will lead to even more lowering of $\mathrm{j} 0$.

Such obvious distortions in the configuration of electrical networks force to return to the well-known problem of optimizing their rated voltage. The method of undetermined Lagrange multipliers, worked out in [5] for this class of problems, will be used. Assume that 
condition (2) is satisfied. Then the second and third terms of (1) will be equal to each other and their sum, taking into account (3), will be:

$$
2 \cdot 3.1 s=2 \cdot 3.1 \sqrt{8.7 / 3.1} I=10.4 I
$$

The resulting costs for the electricity transmission over a distance 1 are written down as $\mathrm{C}=\mathrm{C}_{\mathrm{L}} \mathrm{l}+\mathrm{C}_{\mathrm{TS}}$. Take for example:

$$
\begin{gathered}
C_{\mathrm{TS}}=C_{\mathrm{KTS}}=K(401+1.29 S+25.94 U)= \\
=1.35(401+1.29 \sqrt{3} I U+25.94 U)=541+3 I U+35 U
\end{gathered}
$$

Then taking into account (1), (4) and (5), it can be written:

$$
\begin{aligned}
C & =719 l+10.4 I l+541+3 I U+35 U= \\
& =541+719 l+3 I U+35 U+10.4 I l
\end{aligned}
$$

The cost function (6) is minimized at some fixed value of the power $\mathrm{S}$, i. e. we solve the problem $\mathrm{dC}=0$ under the condition (the constraint equation) that $\mathrm{S} / \sqrt{3}$ $=$ IU by the Lagrange method.

The Lagrange function is composed as following: $\mathrm{C}=719 \mathrm{I}+10.4 \mathrm{Il}+541+3 \mathrm{IU}+35 \mathrm{U}=541+7191+3 \mathrm{IU}+35 \mathrm{U}+$ $+10.4 \mathrm{Il}+\lambda(\mathrm{S} / \sqrt{3}-\mathrm{IU})$.

According to the Lagrange method, there exists a coefficient $\lambda$ such that:

$$
\begin{gathered}
\partial C / \partial U=3 I+35-\lambda I=0 \\
\partial C / \partial I=3 U+10.4 l-\lambda U=0
\end{gathered}
$$

From (7) and (8) we have:

$$
\begin{gathered}
I(\lambda-3)=35 ; I=35 /(\lambda-3) \\
U(\lambda-3)=10.4 l ; U=10.4 l /(\lambda-3)
\end{gathered}
$$

Substituting the values of I and U from (9) and (10) into the constraint equation, we obtain:

$$
\lambda=25 \sqrt{l / S}+3
$$

Taking into account (8) and (11), we have:

$$
3 U+10.4 l-\lambda U=3 U+10.4 l-(25 \sqrt{l / S}+3) U=0
$$

From which the optimal network voltage is:

$$
U=10.4 l /(25 \sqrt{l / S}) \approx 0.4 \sqrt{l S}
$$

Condition (12) is derived for the simplest case of a load concentrated at one point, spaced from the power center by a distance 1 . With a load uniformly distributed along the line, the power losses in the limit will be three times less. The loss of electric power is corresponded by the term 10.41 in the above formulas. Consequently:

$$
U=0.4 \sqrt{l S} / 3=0.13 \sqrt{l S}
$$

Therefore, it follows from (12) and (13) that the optimum voltage for fixed power values and the distance of electric power transmission can vary over a wide range depending on the accepted design conditions:

$$
U=0.13 \div 0.4 \sqrt{l S}
$$

The formula (14) is used for the analysis of the preferred voltage level of the regional electric network with the characteristics from Tables 1 and 2 . The average length of the backbone section of the network is $28 \mathrm{~km}$ (Table 1). Taking into account its sectionalizing in the normal mode, we can assume $1 \approx 28 / 2=14 \mathrm{~km}$. The average load of the fragment in the maximum load mode is $2879 \mathrm{~kW}$, whence $\mathrm{S} \approx 2879 / 2=1440 \mathrm{kV} \cdot \mathrm{A}$. The optimum voltage according to (14) will be $19-57 \mathrm{kV}$.

It is necessary to be cautious to the upper limit of $57 \mathrm{kV}$. With the transfer to $35 \mathrm{kV}$, the design of the $35 / 0.4 \mathrm{kV}$ TS is significantly more complicated and heavier, but which is most importantly, the cost of OHL is 3-4 times higher compared to $10-20 \mathrm{kV}$ OHL. As a consequence, with other things being equal, the cost of the $35 \mathrm{kV}$ network is 1.5-2.5 times (on average 1.8) higher than for networks of 10-20 kV (especially when using transformers of relatively small, up to $100 \mathrm{kV} \cdot \mathrm{A}$, power). Justification of the inexpediency of the 10/0.4 transformation replacement by $35 / 0.4 \mathrm{kV}$ (except for specific areas of oil production in the northern regions) has been considered in a large number of publications [2, 3 , 11, etc.] over many years and the authors are in solidarity with this.

\section{Conclusion}

At this time interval, the cost characteristics of the elements of the 10 (6) and $20 \mathrm{kV}$ overhead networks were either equalized (for overhead lines) or got significantly closer (for transformer substations), which allows to justify the widespread expediency of applying the nominal voltage of $20 \mathrm{kV}$ in the power systems of Russia. This will ensure, at practically the same costs for ownership of the network, a doubling of its transmission capacity, which is extremely important for the implementation of new consumers technological connections.

\section{References}

1. A.A. Glazunov, S.A Gelikonskij, Electricity 11, 24 (1948)

2. YA.M. CHervonenkis, L.M. Finger, Electricity 7, 11 (1965)

3. A.G. Zaharin, N.S. Kanakin, Electricity 1, 6 (1966)

4. A.V. Mayorov, K.A. Osintsev, A.V. Shuntov, Electricity 9, 34 (2017)

5. R. Pelisier, Energy systems (Higher School, Moscow, 1982)

6. Electrical Installations Code (KNORUS, Moscow, 2010)

7. A.I. Khalyasmaa, S.A. Eroshenko, D. Bogdanov, ICSESS November, 75 (2017)

8. A.I. Khalyasmaa, S.A. Dmitriev, A.M. Romanov, RTUCON, (2016) 
9. Company standard 34.01-21.1-001-2017, Electrical distribution network 0.4-110 kV. Requirement for technological design (PJSC ROSSETI, Moscow, 2017)

10. EH.N. Zuev, ELEKTRO 1, 44 (2000)

11. V.P. Frajshteter, A.S. Mart'yanov, Oil industry 4, 117 (2011)

12. N.A. Moguil'nittskii, B.S. Shulov, Application of $20 \mathrm{kV}$ voltage in Latvian SSR (Gosenergoizdat, Leningrad, 1963) 